\title{
Cuidado de recém-nascidos por mães adolescentes primíparas no domicílio
}

Care with newborn babies by primiparous adolescent mothers at home

Cuidado de los recién nacidos de madres adolescentes primíparas en casa

\section{Mayane Trindade da Silva ${ }^{\mathrm{I}}$, Aisiane Cedraz Morais ${ }^{\mathrm{II}}$, Jairo Caique de Araújo ${ }^{\mathrm{III}}$, Ariane Cedraz Morais ${ }^{\mathrm{IV}}$, Sinara de Lima Souza ${ }^{\mathrm{V}}$, Ana Celi Silva Torres Nascimento ${ }^{\mathrm{VI}}$}

\begin{abstract}
Resumo: Objetivo: compreender a forma de cuidado das mães adolescentes primíparas aos seus filhos recémnascidos no domicílio. Método: trata-se de um estudo qualitativo, descritivo e exploratório, realizado no município de Feira de Santana - Bahia, tendo como participantes sete adolescentes primíparas. A coleta de dados aconteceu de setembro a novembro de 2018, os quais foram analisados por meio da Análise de Conteúdo de Bardin. Resultado: evidenciaram que a rotina do cuidar do filho recém-nascido baseia-se nos cuidados relacionado à higiene, alimentação, sono e repouso; possuindo interferência direta da cultura. Além disso, identificou-se que as adolescentes recebem apoio de membros da família para cuidar do recém-nascido e deparam-se com dificuldades associadas ao cuidado diário. Conclusão: as mães se demonstraram zelosas e dedicadas, suprindo as necessidades básicas do recém-nascido com competência, contanto com o auxílio de pessoas que compõe suas redes de suporte social.
\end{abstract}

Descritores: Adolescente; Mães; Recém-nascido; Cuidado da Criança; Enfermagem materno-infantil

Abstract: Objective: to understand how primiparous adolescent mothers care for their newborns at home. Method: this is a qualitative, descriptive and exploratory study, conducted in the city of Feira de Santana, Bahia, whose participants were seven primiparous adolescents. Data collection occurred from September to November 2018, which were analyzed through the content analysis of Bardin. Result: the routine of care with the newborn child is based on care related to hygiene, feeding, sleep and rest, with direct cultural interference. Furthermore, the adolescents receive support from family members to take care of the newborn and face difficulties associated with

\footnotetext{
I Enfermeira, graduada pela Universidade Estadual de Feira de Santana. Feira de Santana - Bahia, Brasil. E-mail: maayantrindade@gmail.com. ORCID: https://orcid.org/0000-0003-2205-4918.

II Enfermeira, Doutora em Enfermagem pela Escola de Enfermagem da Universidade Federal da Bahia. Feira de Santana - Bahia, Brasil. Email: aisicedraz@hotmail.com. ORCID: https://orcid.org/0000-0001-9547-6914.

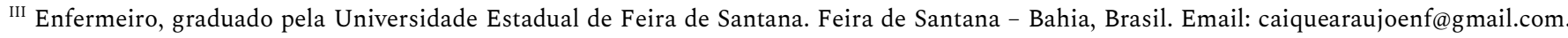
ORCID: https://orcid.org/0000-0002-9317-6448.

IV Enfermeira, Mestre em Enfermagem pela Escola de Enfermagem da Universidade Federal da Bahia. Feira de Santana - Bahia, Brasil. Email:enfarianecedraz@hotmail.com. ORCID: https://orcid.org/0000-0001-9445-4596

v Enfermeira, Doutora em Ciências pela Escola de Enfermagem da Universidade de São Paulo. Feira de Santana - Bahia, Brasil. Email: sinaradd@yahoo.com.br. ORCID: https://orcid.org/0000-0001-8003-2093

${ }^{V I}$ Enfermeira, Mestre pelo Mestrado Profissional em Enfermagem da Universidade Estadual de Feira de Santana. Feira deSantana-Bahia, Brasil. Email:celitorres19@hotmail.com. ORCID: https://orcid.org/0000-0003-2738-6110
} 
daily care. Conclusion: mothers showed to be zealous and dedicated, meeting the basic needs of the newborn with competence, receiving the aid of people that compose their social support networks.

Descriptors: Adolescent; Mothers; Infant, Newborn; Child Care; Maternal-child Nursing

Resumen: Objetivo: comprender la forma de cuidado a madres adolescentes primíparas a sus recién nacidos en casa. Método: este es un estudio de tipo cualitativo, descriptivo y exploratorio realizado en el municipio de Feira de Santana, Bahía, teniendo como participantes siete adolescentes primíparas. La recogida de datos se produjo desde septiembre hasta noviembre de 2018, siendo analizados por medio del análisis del contenido de Bardin. Resultado: la rutina de cuidado para el hijo recién nacido se basa sobre los cuidados relacionados con la higiene, la alimentación, el sueño y el descanso, con la injerencia directa de la cultura. Además, las adolescentes reciben el apoyo de los miembros de la familia para cuidar del recién nacido y enfrentan dificultades relacionadas con el cuidado diario. Conclusión: las madres se demostraron celosas y dedicadas, suministrando a las necesidades básicas del recién nacido con competencia, siempre con la ayuda de las personas que componen sus redes de apoyo social.

Descriptores: Adolescente; Madres; Recién Nacido; Cuidado del Niño; Enfermería maternoinfantil

\section{Introdução}

A adolescência é compreendida como uma etapa do desenvolvimento humano entre a infância e a vida adulta, que além de ser caracterizada por transformações comportamentais e biológicas é permeada por crises e conflitos. ${ }^{1}$ Para além das mudanças físicas, caracteriza-se por ser um importante período no ciclo existencial do indivíduo, no qual começa a surgir o empoderamento pessoal, familiar e social.

Essa etapa da vida é associada ao momento em que ocorre o desenvolvimento dos processos psicológicos e dos papéis de identificação com o adulto; período em que a rotina infantil é questionada e reelaborada, gerando a necessidade de construção de uma identidade própria, envolvendo o desenvolvimento afetivo-sexual. Neste, quanto mais precoce acontece o início das relações sexuais, maior a repercussão negativa sobre a vida reprodutiva e sexual da jovem, representada pelo maior número de gestações e de parceiros sexuais, respectivamente. ${ }^{2}$

A gravidez na adolescência é responsável por introduzir a adolescente na vida adulta, culminando em uma nova busca por sua identidade, com novos conflitos, e novas crises, trazendo a necessidade de reestruturação e mais um reajuste pessoal e social para a redefinição de papéis. ${ }^{3}$ 
Sendo assim, essa gestação será um momento rodeado de descobertas, que faz com que a adolescente viva constantemente com sentimentos de ansiedade, expectativas, incertezas, frustrações e insegurança, que permeiam desde a confirmação da gravidez até o período pós-parto.

Durante o puerpério, a adolescente vive um período de adaptação, necessitando, na maioria das vezes, de ajuda para se adequar à situação fisiológica de nutriz e ao novo papel social de mãe, que somado à inexperiência dos cuidados, à insegurança e ao medo, por ser algo desconhecido e faz com que estas, transfiram inicialmente o cuidado do Recém-nascido (RN) para as avós, tias, ou outros membros da sua rede social; e gradualmente passam a compartilhar com elas essas tarefas, para que ganhem autonomia e assumam posteriormente de forma completa os cuidados dos seus filhos. Por isso, a prática de cuidado ao filho tende a ser estabelecida de acordo com o meio cultural, econômico, social e relacional no qual a adolescente está inserida. ${ }^{4}$ Assim, emerge a problemática de estudo para conhecer o modo de cuidado dessas adolescentes e a implicação do mesmo para o pleno desenvolvimento destas e dos seus filhos.

Deste modo, configura-se a seguinte questão de pesquisa: como as mães adolescentes primíparas cuidam dos seus filhos recém-nascidos no domicílio? Portanto, tem-se como objetivo compreender a forma de cuidado das mães adolescentes primíparas aos seus filhos recém-nascidos no domicílio.

\section{Método}

Para compreender como as mães adolescentes primíparas cuidam dos seus filhos recémnascidos no domicílio, este estudo tem como proposta metodológica a abordagem qualitativa de caráter descritivo e exploratório. A pesquisa foi desenvolvida no município de Feira de Santana no interior da Bahia especificamente na Unidade Saúde da Família (USF) do Povoado de São José, Distrito de Maria Quitéria, no período de setembro a novembro de 2018. Participaram do 
estudo sete puérperas adolescentes que tinham idade entre 12 e 19 anos, com filhos recémnascidos, cadastradas nesta USF.

Foram incluídas as mães adolescentes primíparas com filhos que possuíam idade entre 05 e 29 dias, cadastrados na USF do Povoado de São José. Essas mães foram selecionadas em dias de consulta de puericultura na unidade e a enfermeira do setor sinalizava para a pesquisadora as possíveis adolescentes. Foram excluídas as mães adolescentes as quais o filho fosse portador de alguma doença crônica de origem genética e/ou adquirida (uma vez que esta condição implica a adoção de cuidados especializados); mães com alguma condição que dificultasse a coleta de dados, como surdez e/ou mudez (pela limitação da pesquisadora em outra forma de comunicação diante da técnica de coleta escolhida).

A fim de garantir o anonimato das entrevistas, as adolescentes foram identificadas por pseudônimos correspondentes a nomes de sentimentos escolhidos pelas próprias entrevistadas. Além de possuírem livre escolha para participar do estudo, também tiveram para desistir a qualquer tempo, sem qualquer tipo de represália, assegurando o princípio da autonomia.

Entre as adolescentes estudadas, duas delas tinham 16 anos, 4 possuíam 18 anos e as outras duas, 19 anos. Quatro delas se autodeclaravam como negras e três como pardas, duas possuíam primeiro grau incompleto e as outras seis não chegaram a completar o segundo grau, duas estavam solteiras e as demais em união estável. As solteiras moravam com seus pais e irmãos, as demais com marido e filho. Todas declaravam ser católicas $(n=7)$ e com renda familiar em torno de um salário mínimo.

A técnica de coleta de dados ocorreu por meio da entrevista semiestruturada por possibilitar interação entre a pesquisadora e a entrevistada, além de permitir a percepção de sentimentos, emoções e valores que poderão ser transmitidas nas falas das participantes. 
5 | Silva MT, Morais AC, Araújo JC, Morais AC, Souza SL, Nascimento ACST

As entrevistas foram realizadas, no consultório de Enfermagem, onde não havia o risco de interrupção. As entrevistadas estavam acompanhadas pelo recém-nascido e por sua genitora, a qual aguardava na sala de espera até finalizar a entrevista para manter a privacidade.

Diante da concordância da adolescente e seu responsável a participar do estudo, foi apresentado o Termo de Consentimento Livre e Esclarecido (TCLE) e Termo de Assentimento Livre e Esclarecido (TALE). Dessa forma, era esclarecido o procedimento para coleta de dados e era solicitada às puérperas permissão para que seus depoimentos fossem gravados. Todas as adolescentes selecionadas, concordaram em participar da pesquisa. Utilizamos as perguntas norteadoras: 1. Fale-me como você cuida do(a) seu(sua) filho(a) em casa; 2. Você recebe apoio/ajuda de alguém para cuidar do(a) seu(sua) filho(a) em casa? Fale-me sobre isso; e 3. Quais as dificuldades e facilidades encontradas por você na realização do cuidado cotidiano do(a) seu(sua) filho(a) em casa?

As entrevistas tiveram uma média de trinta minutos de duração, posteriormente os dados foram transcritos e a análise dos dados ocorreu por meio da Análise Temática proposta por Bardin ${ }^{5}$ na intenção de explicar o que está além dos significados imediatos expressos nos discursos das mães adolescentes no processo de cuidar do filho recém-nascido no domicílio. As informações foram agrupadas em categorias e adicionadas, em cada uma, respostas semelhantes, por permitir melhor organização do trabalho, sistematizando os dados obtidos com o objeto de estudo.

O presente trabalho respeitou os aspectos éticos adotados a partir da Resolução 466/2012 do Conselho Nacional de Saúde, que diz respeito à pesquisa envolvendo seres humanos. ${ }^{6}$ Além disso, foi encaminhado para o Comitê de Ética em Pesquisa da Universidade Estadual de Feira de Santana (CEP/UEFS), apreciado e autorizado no dia 18 de julho de 2018 para realização dessa investigação, com parecer de número 2.775 .764 . 
Cuidado de recém-nascidos por mães adolescentes primíparas no domicílio | 6

\section{Resultados e discussão}

Buscando compreender a forma como as mães adolescentes primíparas cuidam dos seus filhos recém-nascidos no domicílio, os resultados compõem-se de quatro categorias: Rotina de Cuidado com o Recém-nascido; Influências transgeracionais para o cuidado; Suporte Social da Adolescente Primípara e Dificuldades da Mãe Adolescente para cuidar do Recém-nascido.

\section{Rotina de cuidado com o recém-nascido}

O cuidado faz parte da existência do ser humano, que para crescer e se desenvolver de forma saudável necessita ser cuidado ao longo de todas as etapas do ciclo de vida; dessa forma, o RN encontra-se numa etapa da vida totalmente dependente de cuidados. Sendo assim, as mães assumem um papel importante em todo esse processo: o de cuidar e educar.

Para as mães entrevistadas, fica evidente que a rotina do cuidar do filho RN constitui-se nos cuidados relacionado à higiene, alimentação, sono e repouso do $\mathrm{RN}$, como pode ser observado no relato.

Sempre quando eu acordo de manhã eu amamento, dou logo o banho dele, passo a pomada nele para não assar [...] visto a roupa, aí amamento, coloco ele para arrotar e vou e coloco ele deitadinho, aí ele acaba dormindo. (Alegria, 18 anos)

É perceptível que as mulheres já têm internamente organizada uma rotina para cuidar diariamente de seu filho, visto que o cuidado sempre esteve associado à prática das mulheres, o que vem se perpetuando até os dias atuais, nos quais os cuidados cotidianos estão integrados à própria atividade feminina. ${ }^{7}$

Nos relatos das mães também foi possível notar que muitas vezes elas precisam conciliar o cuidado do RN com os afazeres domésticos; desse modo, pode-se compreender que o cuidado do filho insere-se na rotina diária da adolescente, na medida em que esta cria estratégias para 
7 | Silva MT, Morais AC, Araújo JC, Morais AC, Souza SL, Nascimento ACST

incluir todas essas atividades ao que ela fazia antes do nascimento deste, associando-as aos cuidados da casa e dos outros membros da família.

Ela acorda umas 6 horas, eu acordo também, aí troco a fralda, faço o mingauzinho dela [...] depois eu boto ela no berço e vou cuidar da casa, quando ela chora eu vou lá, dou o peito, coloco ela para arrotar, ai eu coloco ela no berço de novo ai volto, faço as coisas da casa, arrumo a casa, lavo os pratos, lavo as roupas dela, ai umas 11 horas eu sei que já está na hora do soninho dela, ai eu dou um banho, passo a pomada, visto a roupa, dou o mingau [...] ai ela dorme até umas 12:30, ai eu já terminei de fazer as coisas da casa, ai quando ela acorda eu pego ela e fico com ela no colo. (Confiança, 16 anos)

O depoimento revela como os cuidados com o RN se intercalam diariamente com os afazeres domésticos do cotidiano das mães adolescentes, o que de forma associada interfere inclusive nos estudos dessas adolescentes. As participantes do estudo, especialmente aquelas que moram apenas com o companheiro, também citaram a necessidade de agregar os cuidados com o RN a alguns cuidados relacionados à higiene, limpeza e organização do domicílio, como limpar e arrumar a casa, lavar a louça e a roupa, passar a roupa, cuidar dos animais domésticos, além de cozinhar para os outros membros da família.

\section{Influências transgeracionais para o cuidado}

$\mathrm{Na}$ fase puerperal, a influência da família é acentuada nas decisões de cuidado ao RN, posto que as puérperas estão fragilizadas, susceptíveis à ansiedade, e rodeadas de dúvidas, o que contribui para a ocorrência de manifestações de ajuda, por parte de seus familiares, ao repassarem e praticarem seus saberes populares de cuidado. ${ }^{8}$

Em relação aos saberes e práticas das mães, observou-se que as participantes do estudo têm clareza de quais são os saberes e as práticas necessários para prestar o cuidado ao filho e de 
onde provém tal conhecimento que lhes permite executar seu papel de cuidadora. Segundo elas, estes são construídos, principalmente no convívio com as pessoas próximas a elas, pessoas que cuidaram delas, ensinaram-nas a cuidar e que são seus referenciais.

Ao destacar a influência do uso caseiro de plantas medicinais no tratamento de problemas de saúde de crianças, ressalta-se que os chás caseiros são oferecidos às crianças desde os primeiros meses de vida, com a intenção de resolver ou amenizar situações de desconforto ou doença, prática, ${ }^{9}$ principalmente nas comunidades rurais, tal como a comunidade dessas adolescentes.

De vez em quando, quando eu vejo que ele está preso, ai fica se espremendo todo e não consegue fazer cocô, a barriguinha dele fica dura, ai eu dou uma chazinho de erva doce para ver se alivia se ajuda ele a soltar [...] minha mãe e minha vó disseram que eu podia dar sem medo, que faz bem. (Felicidade, 19 anos)

A minha mãe manda eu dar um chazinho de erva doce para ela acalmar e diz que ajuda a soltar também. (Confiança, 16 anos)

Além do uso de chás para resolução de alguns problemas apresentados, o aleitamento do RN é um dos aspectos do cuidado que merece destaque, pois diz respeito à alimentação como um processo que ultrapassa os limites biológicos e envolve aspectos socioculturais e uma rede de relações entre família e profissionais de saúde. Dessa forma, a crença sobre o "leite fraco" ainda se faz presente no cotidiano dessas adolescentes, levando-as a acreditar que a quantidade e qualidade do leite é de pouca produção ou ruim, mistificando a amamentação. Nesse contexto, surgem as práticas baseadas na cultura popular, na resolução da pouca produção láctea, para isto, são usados diversos alimentos e bebidas, considerados, auxiliares, no processo para aumentar a quantidade de leite. ${ }^{10}$ 
9 | Silva MT, Morais AC, Araújo JC, Morais AC, Souza SL, Nascimento ACST

Meu leite não está dando não, é fraco, ele fica sem paciência, aí fíca chorando. (Paz, 16 anos)

Eu acho que meu leite não está sustentando ele não, ai eu dou um mingauzinho de maisena, que é mais forte, minhas tias sempre falavam, porque eu dava o peito e pouco tempo depois ele já estava chorando de novo, ai eu decidi dá o mingau como elas falaram para ver, ele se deu bem, pode até ser errado, mas melhorou, ele parece que fica mais tempo de barriga cheia. (Carinho, 18 anos)

Foi possível identificar nos depoimentos que o mito do leite não sustentar, pode estar apoiado no choro do RN, que geralmente associam à fome ou ao fato do leite não estar suprindo às necessidades da criança. O "leite fraco" é atribuído a um fator cultural, visto que a maioria das mulheres possui o suficiente para sustentar seu filho. Esta percepção errônea pode estar vinculada ao desconhecimento das mães quanto aos valores do seu leite, sobre como o leite materno é produzido e ao fato de associarem-na maioria das vezes o choro do RN à carência de alimento, o que nem sempre é verdadeiro. ${ }^{11}$

Outra prática popular que surgiu durante entrevista relaciona-se aos banhos, como pode ser observado nos depoimentos que seguem.

É bom colocar um pouquinho de álcool na água que vai dar o banho nele, porque ele está se "calombando" por causa do calor, ai a avó do meu marido disse que toda vez que fosse dar o banho nele era para colocar na água que melhorava, ai eu sempre coloco. (Felicidade, 19 anos)

Ela disse que é para eu dar banho nele e colocar seiva, aí todo banho que eu dou eu coloco um pouquinho de seiva. (Alegria, 18 anos)

Evidenciando mais uma vez a incorporação de saberes populares, muitas vezes sem conhecer a razão dessa prática, reproduzindo uma ação pelo senso comum, ou práticas 
intergeracionais. Diante do exposto, o senso de responsabilidade familiar pelo cuidado à saúde dos seus membros é explicitado, entendendo que o processo saúde-doença do indivíduo deve ser atendido profissionalmente, ${ }^{12}$ especialmente ao se tratar de mães adolescentes que requisitam esse suporte da família.

Outra prática popular que surgiu durante as entrevistas relaciona-se à crença do "mal de sete dias”, relacionado ao tétano neonatal.

Minha mãe queria cortar a unha dele [referindo-se ao RN], mas minha vó não deixou não que ele é novinho, disse que faz mal usar tesoura, ela mandou eu ir assoprando que cai. (Paz, 16 anos)

O termo "mal de sete dias" advém historicamente da associação com o tétano neonatal, decorrente de alguns tipos de infecção que o RN está susceptível. Não foram encontrados na literatura estudos que relacionem o tétano neonatal com a prática do corte das unhas, as relações em sua maioria são feitas decorrente da infecção do coto umbilical. No entanto, podese agregar ao fato de que na grande parte dos casos a porta de entrada da bactéria que causa a doença se dá por meio de ferida perfurante ou de materiais pérfuro-cortantes não esterilizados e contaminados; o que poderia justificar o receio das mães adolescentes em utilizar a tesoura para cortar a unha dos seus filhos, evitando machucá-los e/ou infectá-los.

\section{Suporte social da adolescente primípara}

Neste estudo, considerou-se como suporte social o apoio que as mães adolescentes primíparas possuem para desenvolver o cuidado do seu filho no domicílio, que inclui o sistema oferecido pela família ou outras pessoas que se dispõem a ajudá-la. Assim, os resultados discorrem acerca do apoio social oferecido, principalmente, por outras mulheres, dentre as 
quais, destacaram-se a mãe, sogra; mas evidencia também a figura do esposo como colaborador no cuidado do filho.

O suporte social recebido por uma pessoa é necessário para que ela consiga transpor as diversas situações que a vida lhe impõe e está relacionado com os diversos apoios que as pessoas recebem no seu contexto social. ${ }^{13}$ Embora biologicamente aptas para se tornarem mães, as adolescentes, devido à imaturidade psíquica inerente à idade, podem apresentar dificuldade para exercer uma maternidade efetiva, e a figura materna constituiu a principal fonte de apoio e confiança para a adolescente, dentre as mulheres da família. ${ }^{14}$

Eu recebo ajuda de mainha [referindo-se a avó do RN]. Ela que dá o banho dele até hoje, porque eu tenho medo. (Felicidade, 19 anos)

Minha mãe me ajuda, faz as coisas dentro de casa, dá o banho nele, carrega ele, fica com ele no colo quando ele está chorando que eu não tenho paciência, veste a roupa, troca fralda toda vez, faz tudo!(Paz, 16 anos)

Observa-se que diante da insegurança das mães adolescentes em relação aos cuidados rotineiros ao RN, as avós deixam de oferecer o suporte necessário e passam a assumir o papel de mãe, legitimado pelo fato de se considerarem detentoras do saber. Nos cuidados com o RN, as adolescentes contam com o apoio da família, fato que ocorre, principalmente, nos primeiros dias de vida do bebê, período em que se verifica que essas jovens não estão completamente preparadas para assumir o cuidado dos seus filhos; pois, não demonstram as habilidades necessárias para realizar os primeiros cuidados como o banho, o curativo do coto umbilical, entre outros. ${ }^{14}$

Foi possível notar que além do apoio das mulheres da família, algumas receberam o apoio do companheiro para cuidar do filho, situação referida em estudo anterior. ${ }^{15}$ 
Meu marido me ajuda é quem mais me ajuda [...] minha sogra também me ajuda, mas é bem pouquinho. (Amor, 18 anos)

Eu recebo ajuda do meu marido. (Amizade, 18 anos)

Tem-se verificado que, gradualmente, o homem tem atuado para além do suporte econômico da família, está se fazendo presente no cuidado do $\mathrm{RN}$, inclusive no acompanhamento ao longo de seu desenvolvimento. Durante o estudo, as participantes referiram que a ajuda paterna, merece destaque nos cuidados referentes ao auxílio no banho, troca de fralda, segurar no colo e acalmar o RN por meio da conversa.

Entre as entrevistadas, todas referiram a ajuda dos familiares como um aspecto positivo para cuidar da criança no seu primeiro ano de vida. Desse modo, as mães adolescentes tentam superar seus medos e dificuldades no cuidado aos filhos com a ajuda de familiares e sentindo-se auxiliadas no ambiente que as acolhe e, assim percebem-se apoiadas e seguras; sentindo-se apoiadas, desenvolvem maior segurança no cuidado a essas crianças.

\section{Dificuldades da mãe adolescente para cuidar do recém-nascido}

Os sentimentos expressos em relação ao cuidado do RN no domicílio são mistos de preocupação, impaciência, insegurança e responsabilidade. A fragilidade do corpo do RN é apontada pela maioria das adolescentes entrevistadas. Tal fragilidade é associada, principalmente, à presença do coto umbilical e à dificuldade de sustentação do corpo "molinho", que causam insegurança e dificuldade na hora de realizar cuidados de higiene.

Eu senti dificuldade em quase tudo, para dá o banho mesmo, porque ele é bem molinho, ai eu ficava com medo de segurar, de pegar, de deixar cair na 
banheira, de machucar sei lá [...] Eu fiquei com medo de limpar o umbigo também, ficava com medo de machucar ele. (Carinho, 18 anos)

Para mim a parte mais difícil foi dar o banho mesmo, porque como ele era molinho eu ficava com medo de sei lá, vai que ele escorregasse da minha mão e caísse na banheira e limpar o umbigo também eu fiquei com medo de machucar ele. (Amizade, 18 anos)

Tive medo de dar o banho, principalmente da primeira vez [...] ele era muito molinho [...] eu ficava com medo dele escorregar, sei lá, cair na banheira, tão pequenininho, eu não sabia segurar direito [...]. No início eu ficava com medo de limpar o umbigo também, porque eu tinha medo dele sentir dor, de sangrar. (Alegria, 18 anos)

Grande parte das mães entrevistadas relataram ter medo de o RN escorregar e cair imerso na água da banheira e machucá-lo, e por essa razão muitas preferiam que os primeiros banhos fossem dados por membros da família que possuíssem mais experiência. ${ }^{16}$

Nas primeiras semanas após o nascimento também podem surgir dificuldades em relação à amamentação. Muitas vezes, as adolescentes desconhecem o contexto da amamentação ou ainda não estão prontas para tal ato, o que as deixam mais vulneráveis a apresentarem dificuldades e dúvidas ao longo do processo, associando às dificuldades de cuidar do RN ao desconforto inicial do processo de amamentação, como as dores nas mamas, nos mamilos e as fissuras.

Para mim a dificuldade é dá o peito, porque quando ele mama dói, aí eu não gosto, o bico do meu peito está todo machucado já.(Paz, 16 anos)

Eu fiquei com um pouco de receio de dar a mama também, porque nos primeiros dias doía muito. (Amizade, 18 anos)

Às vezes eu achava difícil dar mama para ele, principalmente logo no início, porque meu peito as vezes o leite empedrava e doía demais quando ele mamava. (Carinho, 18 anos) 
Ao analisar os fatores que influenciam na interrupção do aleitamento materno exclusivo, as nutrizes relatam que a maior causa do sofrimento e ansiedade referente a amamentação diz respeito ao trauma mamilar, que podem fazer com que a criança seja amamentada menos vezes, devido às dores que a mulher apresenta. ${ }^{17}$ Destaca-se, entretanto, que mesmo citando as dificuldades com os $\mathrm{RN}$, as participantes afirmaram que os pontos positivos eram mais importantes e que compensavam as experiências ruins.

Desse modo, em virtude das dificuldades encontradas pelas adolescentes primíparas, e da responsabilidade dos profissionais de saúde em prestar as orientações a respeito desse cuidado, torna-se necessária a discussão sobre os aspectos que devem ser abordados para a construção do processo de educação em saúde voltado a esse público.

Assim, a adolescente durante o pré-natal precisa receber informações e orientações pertinentes à gestação, parto e puerpério, informações essas que serão importantes para o enfrentamento desses períodos com maior segurança, harmonia e prazer; além do apoio da família ou rede social. A falta de apoio pode acarretar ${ }^{18} \mathrm{em}$ abandono escolar, isolamento social e problemas de relacionamento com o companheiro e alguns familiares, bem como ressalta-se que os profissionais da saúde no ciclo gravídico-puerperal devem atender às demandas da adolescente e ampliar as suas possibilidades de fontes de apoio social, promovendo, consequentemente, a saúde materno-infantil.

\section{Conclusão}

Os depoimentos das adolescentes primíparas deixam claro que o cuidado dos seus filhos no domicílio ocorre com o auxílio das avós dos $\mathrm{RN}$ ou outras pessoas que compõe suas redes de suporte social. Além disso, ao relatarem a realização do cuidado, essas mães demonstraram-se zelosas, dedicadas, suprindo as necessidades básicas dos filhos com competência. 
Uma das limitações da pesquisa desenha-se pela exclusão da família no objeto de estudo; pois entende-se que para mãe adolescente a família deve ser inclusa na abordagem, não só como promotora do cuidado, mas reconhecendo seu papel junto a esta puérpera. A família é, portanto, essencial no cuidado cotidiano do RN visto que seu apoio é essencial nessas circunstâncias; pois, a nova mãe precisa ser entendida com relação aos seus medos, angústias e adaptação ao novo.

Por receberem ajuda de pessoas mais experientes tanto do seu âmbito familiar, quanto social, foi possível identificar que existem influências culturais no cuidado ao RN no domicílio devido às interações sociais que existem dentro da própria família e sociedade na qual a adolescente está inserida. Desse modo, verifica-se a importância de valorizar os costumes que são repassados de geração a geração como forma de produzir cuidado à saúde das pessoas. Urge, no entanto, a necessidade de implementar essa prática no âmbito do cuidado de enfermagem, reforçando a importância dos profissionais de saúde, e especialmente os enfermeiros, conhecer como esses costumes enviesam a prática diária de cuidar do RN.

Com os resultados, também foi possível observar que a vivência da adolescente primípara no cuidado do seu filho é desenvolvida com enfoque único no bem-estar do mesmo, ficando em segundo plano os cuidados consigo, os estudos, as amizades e sua vida social, demonstrando a necessidade de fornecer suportes sociais a essa jovem para essa fase de sua vida.

Vale ressaltar que o cuidado realizado pelo profissional de Enfermagem não deverá englobar somente os aspectos biológicos do puerpério, mas as experiências subjetivas desta fase, na perspectiva de mudança de papel na sociedade que a adolescente puérpera vivencia com relação aos seus sentimentos frente ao fato de tornar-se mãe e as transformações pessoais e comportamentais que ocorrem.

Por fim, ressalta-se a escassez de estudos com enfoque nos cuidados atribuídos pelas mães adolescentes aos RN no domicílio, evidenciando a necessidade de que novos estudos sejam 
desenvolvidos com esse público a fim de tornar os cuidados por mães adolescentes mais leve e prazeroso, com menos dificuldades e dúvidas.

\section{Referências}

1. Dias PMM, Oliveira JM, Lustosa AP, Lima HKLS, Moreira KAP, Pereira TM. Repercussões da gravidez na adolescência na vida da mulher adulta. Rev Rene (Online). 2017 jan-fev;18(1):106-13. doi: 10.15253/2175-6783.2017000100015

2. Maranhão TA, Gomes KRO, Oliveira DC, Moita Neto JM. Repercussão da iniciação sexual na vida sexual e reprodutiva de jovens de capital do Nordeste brasileiro. Ciênc Saúde Colet. 2017 dez;22(12):4083-94. doi: https://doi.org/10.1590/1413-812320172212.16232015

3. Vieira EM, Bousquat A, Barros CRS, Alves MCGP. Gravidez na adolescência e transição à vida adulta em jovens usuárias do SUS. Rev Saúde Pública (Online). 2017;51:25. doi: https://doi.org/10.1590/s15188787.2017051006528

4. Oliveira EAR, Rocha SS. O cuidado cultural às crianças na dinâmica familiar: reflexões para a Enfermagem. Rev Interdiscip [Internet]. 2015 jan-mar [acesso em 2019 out 09];8(1):227-33. Disponível em: https://revistainterdisciplinar.uninovafapi.edu.br/index.php/revinter/article/view/302/pdf_198

5. Bardin L. Análise de conteúdo. São Paulo: Edições 70; 2011.

6. BRASIL. Ministério da Saúde. Resolução nº 466, de 12 de dezembro de 2012. Diretrizes e normas regulamentadoras de pesquisas envolvendo seres humanos. Brasília, DF, 2013. Disponível em: http://bvsms.saude.gov.br/bvs/saudelegis/cns/2013/res0466_12_12_2012.html. Acesso em: 10 out. 2019.

7. Araújo MGO, Dutra MOM, Leite-Freitas CCS, Guedes TG, Souza FS, Baptista RS. Cuidando de quem cuida: qualidade de vida e sobrecarga de mulheres cuidadoras. Rev Bras Enferm. 2019 jun;72(3):728-36. doi: https://doi.org/10.1590/0034-7167-2018-0334

8. Linhares EF, Marta FEF, Dias JAA, Santos MCQ. Family management influence in the birth of the newborn and prevention of omphalitis. Rev Enferm UFPE On Line [Internet]. 2017 nov [cited 2019 Sept 28];11(11 Suppl):4678-86. Available from: https://periodicos.ufpe.br/revistas/revistaenfermagem/article/view/231209

9. Bonow CT, Ceolin T, Mendieta MC, Piriz MA, Minuto JC, Heck RM. Práticas de cuidado em saúde realizadas às crianças de uma área rural. Ciênc Cuid Saúde. 2019;18(3):e45128. doi: https://doi.org/10.4025/cienccuidsaude.v18i2.45128

10. Rocha SK, Ravelli APX. Práticas culturais de puérperas no aleitamento materno: problemas 
mamários. Rev Triângulo (Online). 2014 jan-jun;7(1):140-57. doi: https://doi.org/10.18554/rt.v7i1.495

11. Rocci E, Fernandes RAQ. Dificuldades no aleitamento materno e influência no desmame precoce. Rev Bras Enferm. 2014 jan-fev;67(01):22-7. doi: https://doi.org/10.5935/0034-7167.20140002

12. Takemoto AY, Zarpelon NF, Rossetto ED. Práticas populares no cuidado infantil: percepção das mães. Rev Rene (Online). 2019;20:1-9. doi: 10.15253/2175-6783.20192040075

13. Molina RCM, Higarashi IH, Marcon SS. Importância atribuída à rede de suporte social por mães com filhos em unidade intensiva. Esc Anna Nery Rev Enferm. 2014;18(1):60-7. doi: 10.5935/1414-8145.20140009

14. Demori CC, Soares MC, Cremonese L, Barreto CN. De mulheres para mulheres: rede social de apoio às adolescentes grávidas. Rev Enferm UFSM. 2018 jun;8(2):247-62. doi: http://dx.doi.org/10.5902/2179769229288

15. Cruz C, Nelas P, Coutinho E, Chaves C, Amaral O. A influência do suporte social na vinculação pai/bebê. Rev INFAD Psicol. 2017;1(3):123-30. doi: https://doi.org/10.17060/ijodaep.2017.n1.v3.981

16. Lopes KDCL, Oliveira Neto JG, Sá GGM, Carvalho DA, Monteiro MM, Martins MCC. Dificuldades nos Cuidados ao Recém-Nascido: Realidades de puérperas primíparas. Rev Saúde Pública Santa Catarina [Internet]. 2015 set-dez [acesso em 2019 out 10];8(3):19-33. Disponível em: http://revista.saude.sc.gov.br/index.php/inicio/article/view/351

17. Amaral LJX, Sales SS, Carvalho DPSRP, Cruz GKP, Azevedo IC, Ferreira Júnior MA. Fatores que influenciam na interrupção do aleitamento materno exclusivo em nutrizes. Rev Gaúch Enferm. 2015;36(1):127-34. doi: http://dx.doi.org/10.1590/1983-1447.2015.esp.56676

18. Cremonese L, Wilhelm LA, Prates LA, Paula CC, Sehnem GD, Ressel LB. Apoio social na perspectiva da puérpera adolescente. Esc Anna Nery Rev Enferm. 2017;21(4):e20170088. doi: https://doi.org/10.1590/2177-9465-ean-2017-0088

\section{Autor correspondente}

Mayane Trindade da Silva

E-mail: maayanetrindade@gmail.com

Endereço: Avenida Transnordestina, s/n - Novo Horizonte - Feira de Santana - Bahia - Brasil.

CEP: $44036-900$

\section{Contribuições de Autoria}

\section{1 - Mayane Trindade da Silva}

Concepção e projeto, análise e interpretação dos dados, redação do artigo, revisão crítica relevante do conteúdo intelectual, aprovação final da versão a ser publicada. 


\section{2 - Aisiane Cedraz Morais}

Concepção e projeto, análise e interpretação dos dados, redação do artigo, revisão crítica relevante do conteúdo intelectual, aprovação final da versão a ser publicada.

\section{3 - Jairo Caique de Araújo}

Análise e interpretação dos dados, redação do artigo, revisão crítica relevante do conteúdo intelectual, aprovação final da versão a ser publicada.

\section{4 - Ariane Cedraz Morais}

Análise e interpretação dos dados, redação do artigo, revisão crítica relevante do conteúdo intelectual, aprovação final da versão a ser publicada

\section{5 - Sinara de Lima Souza}

Análise e interpretação dos dados, redação do artigo, revisão crítica relevante do conteúdo intelectual, aprovação final da versão a ser publicada

\section{6 - Ana Celi Silva Torres Nascimento}

Análise e interpretação dos dados, redação do artigo, revisão crítica relevante do conteúdo intelectual, aprovação final da versão a ser publicada

\section{Como citar este artigo}

Silva MT, Morais AC, Araújo JC, Morais AC, Souza SL, Nascimento ACST. Cuidado de recém-nascidos por mães adolescentes primíparas no domicílio. Rev. Enferm. UFSM. 2020 [Acesso em: Anos Mês Dia]; vol.10 e55: 1-18. DOI:https://doi.org/10.5902/21797692399222 